\title{
PERANCANGAN INTERIOR KANTIN MODERN UNIVERSITAS HARAPAN MEDAN FAKULTAS TEKNIK DAN KOMPUTER BERBASIS 3D
}

\author{
Muchzakhir Bustari ${ }^{\bowtie}$, Sayuti Rahman, Ari Usman \\ Teknik Informatika, Universitas Harapan, Medan, Indonesia \\ Email: zakirbastar1@gmail.com
}

DOI: $\underline{\text { htps://doi.org/10.46880/jmika.Vol5No2.pp169-175 }}$

\begin{abstract}
The era of globalization always changes in terms of knowledge every year. One of them is the presence of technology as a tool to facilitate human work. The use of existing technology is then developed into information. Without information, maybe humans don't know how to see and even use technology as a place for information. One of the information that can be obtained through technology is video. In this video, it will show the interior design of the modern canteen of the engineering faculty and computer fields of the university. With a canteen design using this modern development concept, it can be used as a new canteen development innovation. The canteen's 3D model design is made using a blender software. From this design, animation will be given and implemented into a video. The design process starts from hardware and software, storyboards and sketches, object modeling, presenting textures, presenting animation, rendering, and editing. The result of the video can be used as promotion or interactive multimedia to the community or certain parties.
\end{abstract}

Keyword: 3D Model, Blender, Canteen, Promotion, Interactive Multimedia.

\begin{abstract}
ABSTRAK
Era globalisasi selalu berganti dari segi pengetahuan setiap tahunnya. Salah satunya dengan hadirnya teknologi sebagai alat untuk mempermudah pekerjaan manusia. Pemanfaatan teknologi yang sudah ada kemudian dikembangkan ke dalam informasi. Tanpa adanya informasi, mungkin manusia tidak tahu bagaimana cara mengetahui dan bahkan menggunakan teknologi sebagai tempat informasi. Salah satu informasi yang bisa didapatkan melalui teknologi yaitu video. Pada video ini, akan menampilkan rancangan interior kantin modern universitas harapan medan fakultas teknik dan komputer. Dengan adanya rancangan kantin dengan menggunakan konsep interior modern ini, dapat dimanfaatkan sebagai inovasi pengembangan terbaru kantin. Rancangan model 3D kantin dibuat menggunakan software blender. Dari rancangan tersebut, akan diberikan animasi dan diimplementasikan menjadi video. Proses perancangan dimulai dari identifikasi perangkat keras dan perangkat lunak, storyboard dan sketsa, pemodelan objek, pemberian tekstur, pemberian animasi, rendering, sampai dengan proses penyuntingan. Hasil akhir dari video dapat digunakan sebagai promosi maupun multimedia interaktif kepada masyarakat ataupun pihak tertentu.

Kata Kunci: Model 3D, Blender, Kantin, Promosi, Multimedia Interaktif.
\end{abstract}

\section{PENDAHULUAN}

Era globalisasi selalu berganti dari segi pengetahuan setiap tahunnya. Baik itu di pekerjaan maupun kegiatan keseharian kita. Di balik pekerjaan yang dilakukan manusia setiap harinya, terlintas pemikiran bahwa manusia butuh sesuatu yang dapat mempermudah pekerjaan mereka. Dari pemikiran tersebut, mulai banyak pengujian yang dilakukan agar mencapai kemudahan tersebut. Salah satu hasil yang dicapai oleh manusia serta dipakai hingga sekarang ini yaitu teknologi.

Teknologi membantu manusia diberbagai pekerjaan. Dari yang tampak wujudnya maupun dalam berbentuk digital di dalam perangkat elektronik.
Pemanfaatan teknologi yang sudah ada kemudian dikembangkan ke dalam informasi. Salah satu informasi bisa didapatkan melalui video. Video menjadi sarana informasi untuk dipelajari, dibuat, hingga diinformasikan kepada masyarakat untuk diketahui. Misalnya digunakan pada Rancangan Interior Kantin Modern Universitas Harapan Medan Fakultas Teknik dan Komputer. Dengan adanya rancangan kantin dengan menggunakan konsep interior modern ini, dapat dimanfaatkan sebagai inovasi pengembangan terbaru kantin. Pembuatan model kantin akan dibuat melalui 3D (3 Dimensi). Dengan adanya model 3D, memberikan kemudahan bagi pengguna untuk menampilkan bentuk sesuai dengan 
ukuran dan dapat memperlihatkan bentuk secara nyata sehingga dapat memberikan informasi dari model 3D (Cahyono \& Rafitricia, 2017).

Kemudian, diberikan animasi ke beberapa objek, dan diimplementasikan ke dalam video animasi. Kemudian, video animasi tersebut bisa digunakan sebagai promosi untuk memperkenalkan inovasi terbaru dari kampus kepada masyarakat. Selain itu, video animasi bisa dimanfaatkan ke dalam multimedia interaktif untuk mempresentasikan video menjadi lebih variatif kepada pihak tertentu.

Pada penelitian ini, penulis memilih software Blender sebagai media untuk pembuatan animasi dan editing video rancangan kantin. Baik itu 3 Dimensi maupun video promosi. Selain itu, penulis menggunakan software Macromedia Flash untuk membuat multimedia interaktif dalam mempromosikan rancangan kantin.

Berdasarkan pemaparan pada penjelasan diatas, terdapat beberapa pokok permasalahan yang akan dibahas yaitu, Apakah informasi dari interior kantin modern yang diimplementasikan ke dalam video mendapatkan respon yang sesuai yang diinginkan penulis ketika disebarkan kepada masyarakat sebagai promosi?

Adapun manfaat serta tujuan dari penelitian ini yaitu dapat menghasilkan video dengan memanfaatkan model 3D melalui animasi dan editing video sebagai promosi maupun multimedia interaktif kepada lingkungan kampus ataupun pihak tertentu. Dengan demikian animasi yang dibuat diharapkan menjadi animasi yang dapat diimplementasikan ke bidang lainnya.

\section{TINJAUAN PUSTAKA Interior}

Interior adalah bagian dalam gedung atau sering kali diartikan sebagai komponen pendukung yang bisa mempercantik ruang di dalam gedung. Dalam buku ilustrasi interior, desain interior adalah perencanaan, penataan, serta merancang ruang dalam bangunan (Sonjaya \& Zahra, 2017).

\section{Promosi}

Promosi adalah unsur dalam bauran pemasaran perusahaan yang di dayagunakan untuk memberitahukan, membujuk, dan mengingatkan tentang produk perusahaan. Dalam promosi terdapat komunikasi yang harus dibangun oleh pihak produsen kepada para konsumennya, apalagi dengan para pelanggan setianya. Sebab dengan membangun komunikasi yang baik dan jelas, akan memberikan pengaruh positif antara kedua belah pihak dalam rangka membangun saling percaya, tanpa ada rasa curiga satu sama lain (Islami \& Sembada, 2017).

\section{Multimedia}

Pengertian multimedia menurut istilah adalah penggunaan sarana (media) yang menyajikan kombinasi (gabungan) berbagai elemen informasi seperti video, teks, suara, graphics maupun gambar yang bersifat interaktif yang bertujuan menyampaikan informasi atau sekedar memberikan hiburan kepada si penerima (Awulle et al., 2016).

\section{Blender}

Blender adalah sebuah software open source yang memungkinkan penggunanya untuk melakukan pembuatan konten 3D yang interaktif. Software ini menawarkan fungsi penuh untuk melakukan modelling, texturing, rendering, pembuatan animasi, pos produksi, dan pembuatan game (Rapi et al., 2019).

\section{Macromedia Flash}

Macromedia Flash merupakan suatu program aplikasi yang digunakan untuk mengolah gambar vector dan animasi. Objek-objek yang dapat dioleh untuk membuat animasi selain vector (yang dibuat secara langsung di flash) juga gambar-gambar bitmap yang di impor, objek sound dan objek avi (Komputer, 2002).

\section{Model 3D}

Model 3 Dimensi (Model 3D) merupakan bentuk simulasi dalam memahami suatu konsep model geometri yang berisi informasi gambaran objek. Keunggulan utama dari 3D adalah visualisasi objek yang tampak lebih nyata sehingga mendekati bentuk aslinya. Objek 3D digambarkan ke dalam layar untuk menciptakan pemodelan dari keseluruhan dunia buatan kedalam simulasi dunia nyata. Objek dalam layar ditransformasikan ke titik-titik koordinat dan dialokasikan untuk membentuk imajinasi sebuah dunia 3 Dimensi (Adillasari, 2018).

\section{Animasi}

Animasi adalah video yang diperoleh dari kumpulan gambar yang diolah sesuai keinginan hingga menjadi sebuah gambar bergerak dan bercerita (Pramudia, Apriyani, \& Prasetyaningsih, 2016). Animasi dibuat berdasarkan manfaat media yang digunakan untuk berbagai kebutuhan, diantaranya animasi sebagai media hiburan, media presentasi, 
media iklan/promosi, media alat bantu, dan pelengkap suatu objek atau tampilan.

\section{METODE PENELITIAN}

Teknik pengumpulan data pada penelitian ini adalah sebagai berikut:

1. Studi Literatur

Pada tahapan ini, studi literatur dilakukan dengan pengumpulan bahan pustaka atau referensi mengenai tata cara membuat bangunan dari modelling 3D, animasi 3D, editing video dan mulmedia interaktif yang bersumber dari bukubuku dan jurnal-jurnal dari penelitian yang sudah ada sebelumnya.

2. Analisis Perancangan dan Implementasi

Pada tahapan ini, dilakukan perancangan story board, sketsa, mengimplementasikan kantin dalam modelling 3D, simulasi animasi karakter ketika berada di dalam kantin dan kondisi kantin.

3. Pengujian dan analisis hasil

Pada tahapan ini, pengujian terhadap hasil video animasi 3D mengenai kantin apakah dapat layak dijadikan video promosi dan analisis hasil untuk memeriksa apakah hasil dari penelitian sudah sesuai dengan masalah yang diteliti.

4. Penyusunan Laporan

Pada tahapan ini, akan dilakukan penyusunan laporan dari hasil penelitian yang telah dilakukan menjadi suatu kesimpulan agar didapatkan cara penyelesaian masalah yang lebih jelas.

\section{Kerangka Kerja Pembuatan Modelling Kantin}

Sebelum masuk ke tahapan perancangan kantin, harus dirancang terlebih dahulu kerangka kerja yang berfungsi sebagai alur dalam tahapan pembuatan hasil modelling kantin yang dapat dilihat pada Gambar 1 dibawah ini.

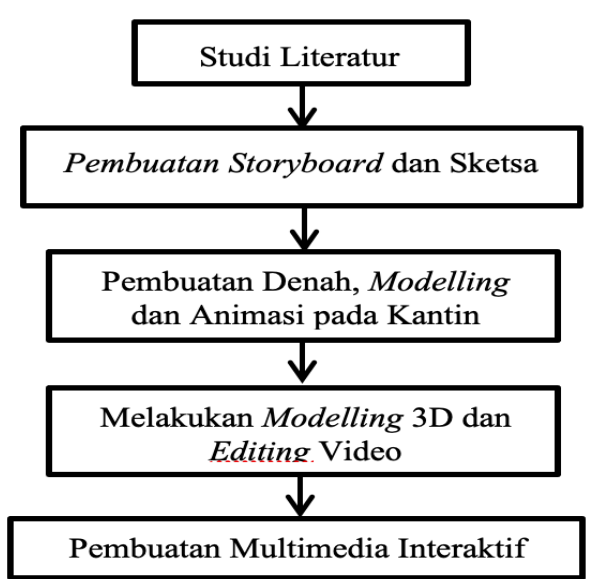

Gambar 1. Kerangka kerja pembuatan Modelling Kantin

\section{Storyboard}

Sebelum membuat animasi, terlebih dahulu untuk membuat alur cerita dari animasi menggunakan storyboard. Berikut alur cerita yang dapat dilihat pada Tabel 1 dibawah ini.

Tabel 1. Storyboard

\begin{tabular}{|c|c|c|c|}
\hline No. & $\begin{array}{c}\text { Ilustrasi Animasi } \\
\text { dalam bentuk } \\
\text { gambar }\end{array}$ & Durasi & Keterangan \\
\hline 1 & & 6 detik & $\begin{array}{l}\text { Menampilkan } \\
\text { Tampilan } \\
\text { Depan Kantin. }\end{array}$ \\
\hline 2 & & $\begin{array}{c}11 \\
\text { detik }\end{array}$ & $\begin{array}{l}\text { Kamera } \\
\text { menampilkan } \\
\text { sekeliling } \\
\text { kantin. }\end{array}$ \\
\hline 3 & 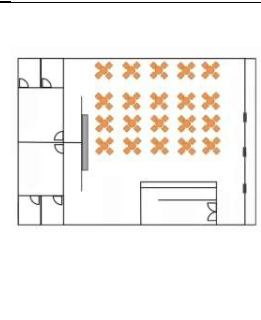 & $\begin{array}{c}19 \\
\text { detik }\end{array}$ & $\begin{array}{l}\text { Kamera } \\
\text { menampilkan } \\
\text { seluruh } \\
\text { ruangan yang } \\
\text { ada di kantin } \\
\text { (tanpa atap) } \\
\text { dari atas. }\end{array}$ \\
\hline 4 & 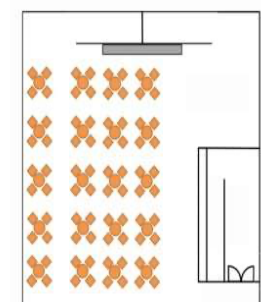 & $\begin{array}{c}11 \\
\text { detik }\end{array}$ & $\begin{array}{l}\text { Kamera } \\
\text { menampilkan } \\
\text { suasana area } \\
\text { makan kantin. }\end{array}$ \\
\hline 5 & & $\begin{array}{c}18 \\
\text { detik }\end{array}$ & $\begin{array}{l}\text { Kamera } \\
\text { menampilkan } \\
\text { suasana dapur } \\
\text { kantin. }\end{array}$ \\
\hline
\end{tabular}




\begin{tabular}{|c|c|c|c|}
\hline 6 & & $\begin{array}{c}25 \\
\text { detik }\end{array}$ & $\begin{array}{l}\text { Kamera } \\
\text { menampilkan } \\
\text { suasana kasir. }\end{array}$ \\
\hline 7 & \begin{tabular}{|l|l|}
07 \\
0
\end{tabular} & $\begin{array}{c}29 \\
\text { detik }\end{array}$ & $\begin{array}{l}\text { Kamera } \\
\text { menampilkan } \\
\text { suasana toilet } \\
\text { pria. }\end{array}$ \\
\hline 8 & \begin{tabular}{|l|l|} 
& $b^{\circ}$ \\
$b^{\circ}$
\end{tabular} & $\begin{array}{c}30 \\
\text { detik }\end{array}$ & $\begin{array}{l}\text { Kamera } \\
\text { menampilkan } \\
\text { suasana toilet } \\
\text { wanita. }\end{array}$ \\
\hline 9 & 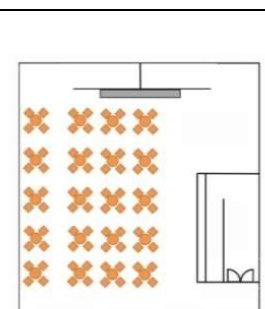 & 9 detik & $\begin{array}{l}\text { Kamera } \\
\text { menampilkan } \\
\text { bangku di area } \\
\text { makan kantin. }\end{array}$ \\
\hline
\end{tabular}

\section{Sketsa}

Untuk mencapai tujuan yang diinginkan oleh penulis, sketsa sangat dibutuhkan untuk meminimalisir kesalahan ketika melaksanakan proses pembuatan. Sketsa akan digunakan untuk menentukan tampilan multimedia interaktif yang dapat dilihat pada Gambar 2. berikut ini.

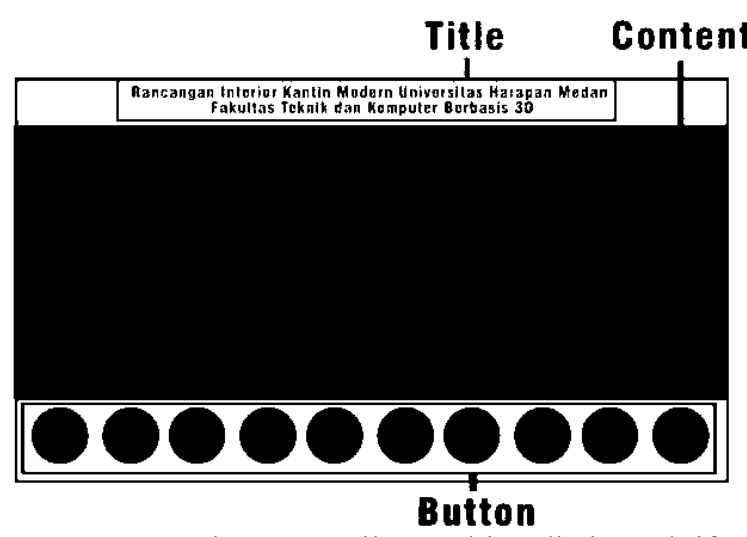

Gambar 2. Sketsa tampilan multimedia interaktif

\section{Modeling 3D}

Dalam rancangan interior kantin ini penulis membuat denah dan ukuran keseluruhan kantin, baik itu dari sisi luar maupun dalam kantin. Selain itu, properti juga berpengaruh dalam menampilkan fisik dari objek yang diambil selama animasi dilakukan pada objek tertentu dalam kantin. Berikut denah dan ukuran keseluruhan kantin yang ada pada Gambar 3. dibawah ini.

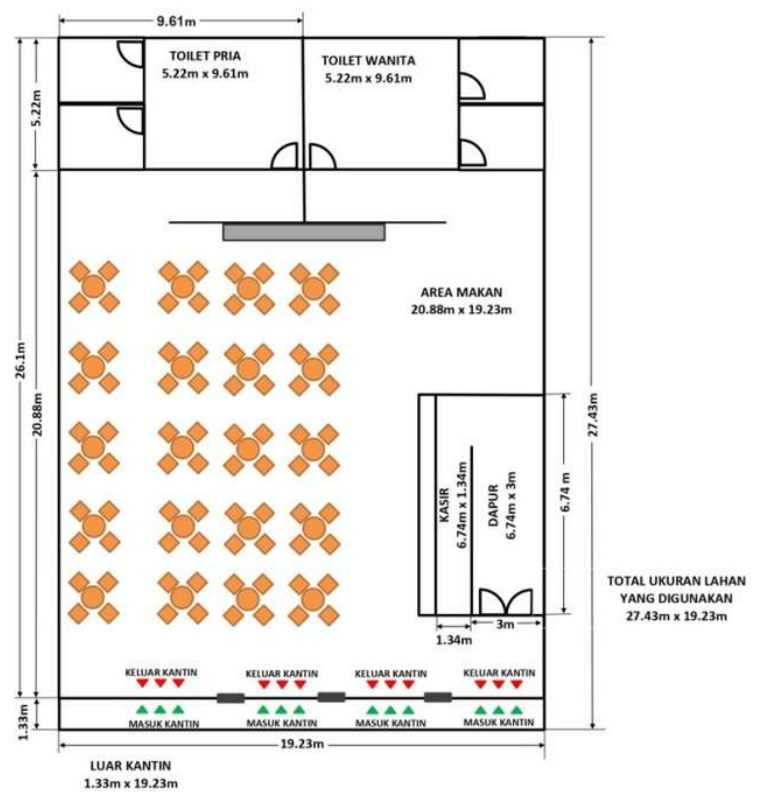

Gambar 3. Denah dan ukuran model interior kantin

Selanjutnya, penulis membuat kantin sesuai dengan ukuran dan tata letak barang yang akan ada di modeling kantin. Dimulai dari pembuatan dinding menggunakan fitur archimesh pada software Blender yang terdapat di Gambar 4.

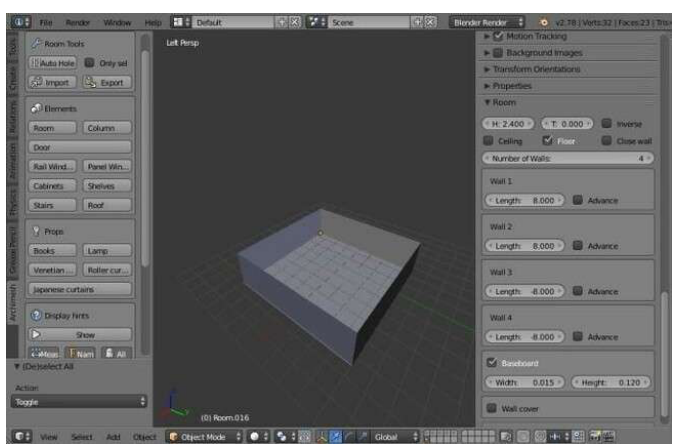

Gambar 4. Penggunaan fitur Archimesh pada software Blender

\section{Penggunaan Aset Karakter di Website Mixamo}

Penulis mengambil aset karakter dan melakukan animasi di dalam website Mixamo. Aset ini digunakan sebagai simulasi yang dilakukan dalam kantin. Untuk aset karakter dapat dilihat pada Gambar 5. 


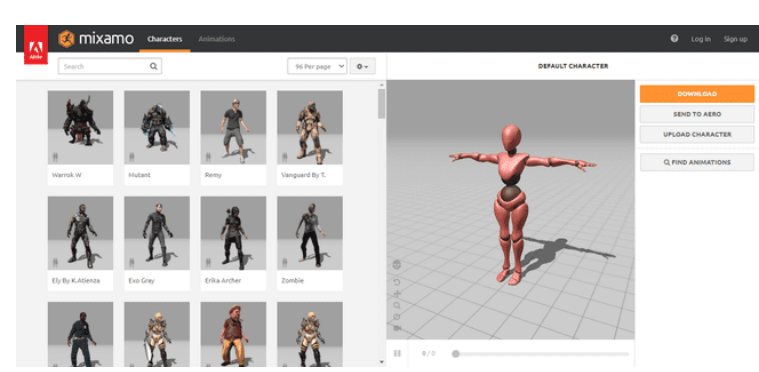

Gambar 5. Mengambil aset model dan animasi di website Mixamo

\section{Menambahkan Camera dan Lamp}

Modelling yang sudah dibuat dan ditambahkan akan dilengkapi dengan camera yang diberi animasi dan lamp untuk mengatur cahaya pada pengambilan animasi yang dapat dilihat pada Gambar 6. dan Gambar 7.

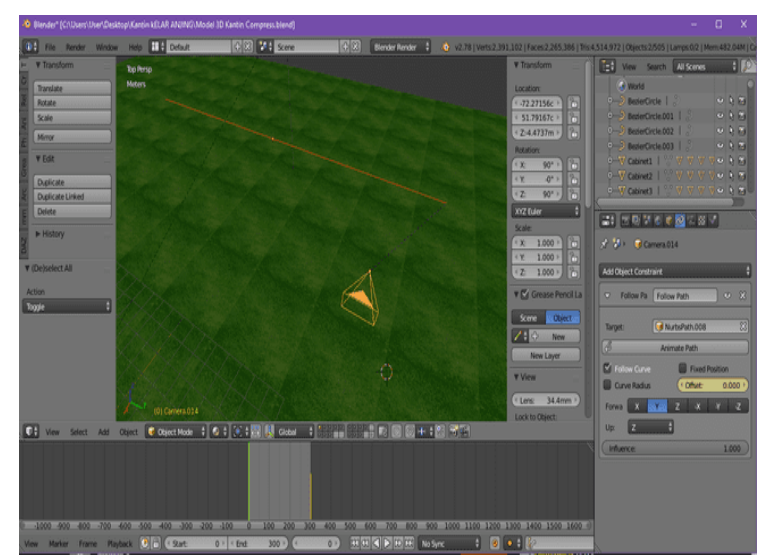

Gambar 6. Memberikan animasi ke camera

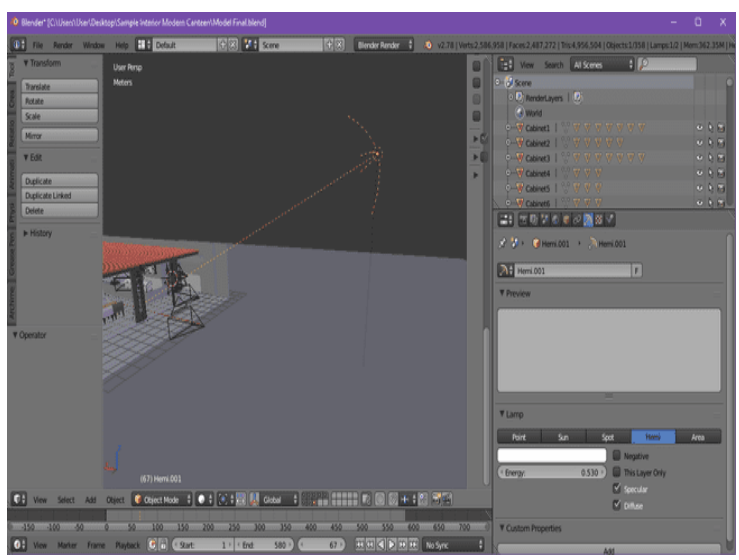

Gambar 7. Pengaturan cahaya menggunakan lamp

\section{Pemberian warna dengan material dan texturing}

Modelling yang sudah ada akan diberikan warna dengan material dan texturing yang ada maupun diambil dari gambar yang dapat dilihat pada Gambar 8 .

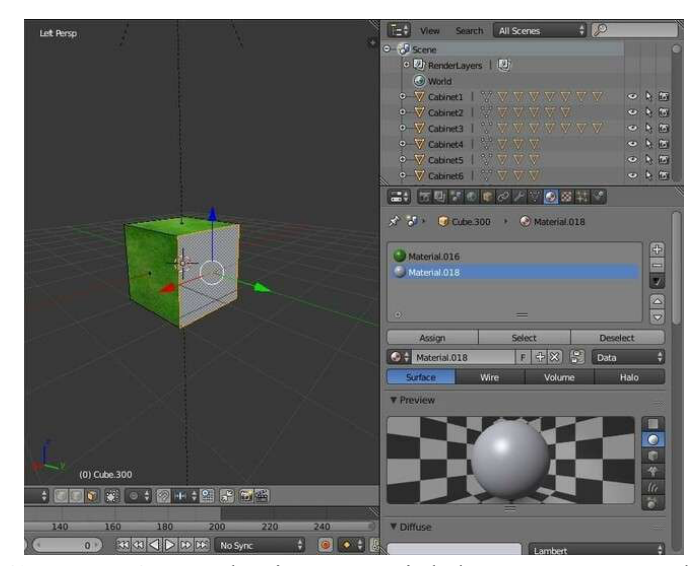

Gambar 8. Pemberian material dan texturing pada objek

Hasil dari modelling kantin yang sudah diletak material dan texturing dapat dilihat pada Gambar 9. dan Gambar 10. berikut ini.

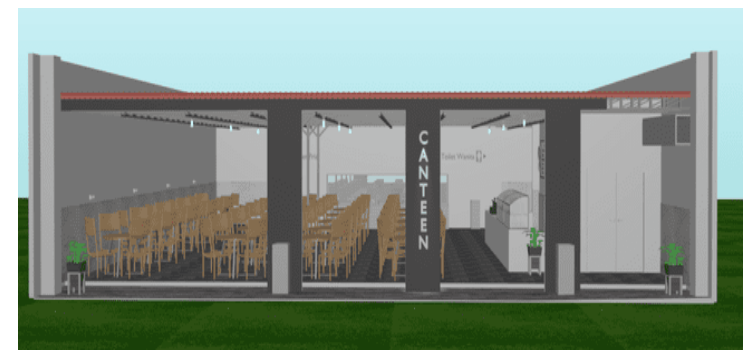

Gambar 9. Tampilan depan modelling interior kantin

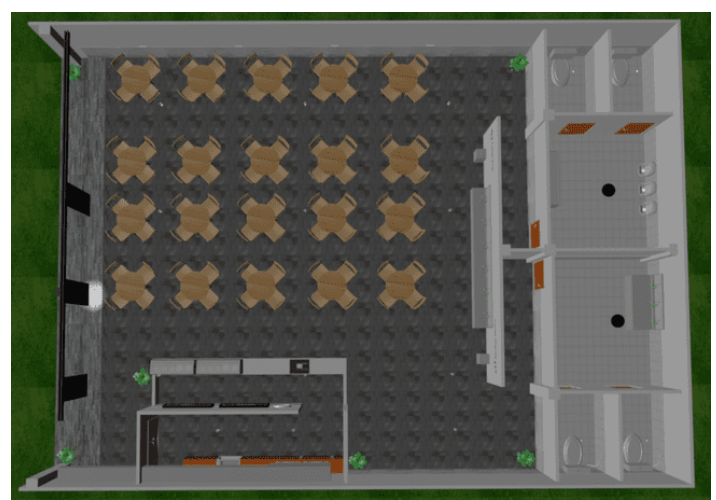

Gambar 10. Tampilan dari atas modelling interior kantin (tanpa atap)

Semua model-model 3D yang telah dirancang juga diberikan material dan texturing agar objek sesuai penulis inginkan. Langkah selanjutnya yaitu pemberian animasi ke beberapa objek yang telah dibuat untuk digerakkan. Kemudian, akan dilakukan rendering untuk mengambil output video dan foto yang diperlukan. Pastikan animasi yang diinginkan susah sesuai, dikarenakan dibutuhkan waktu yang sangat lama dalam melakukan rendering. 


\section{Editing Video}

Setelah dilakukan proses rendering, maka langkah selanjutnya adalah melakukan proses editing video. Pada video animasi yang penulis buat, penulis menggunakan software Blender. Software ini membantu penulis dalam memberikan text, suara maupun transisi pada video animasi yang dibuat.

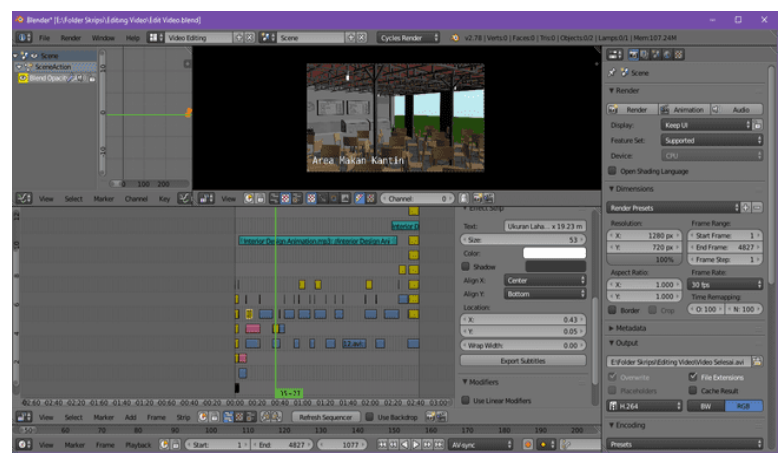

Gambar 11. Proses Editing Video

\section{Multimedia Interaktif}

Selain itu, penulis membuat multimedia interaktif dengan menggunakan software Macromedia Flash 8.0 dan memanfaatkan video animasi kantin yang sudah di rendering agar tampilan lebih variatif ketika dipresentasikan yang dapat dilihat pada Gambar 12 . berikut ini.

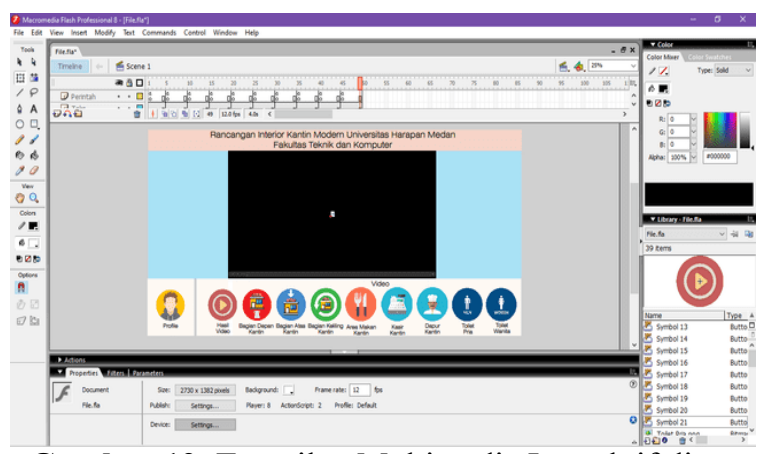

Gambar 12. Tampilan Multimedia Interaktif di software Macromedia Flash 8.0

\section{HASIL DAN PEMBAHASAN}

Video dari hasil rendering yang sudah diimplementasikan kedalam promosi dan multimedia interaktif. Promosi pada video animasi berdurasi 2 menit 40 detik. Untuk bagian dari video animasi promosi akan ditunjukkan bersamaan dengan tampilan video animasi pada multimedia interaktif. Terdapat interaksi yang dapat dilakukan ketika menggunakan multimedia interaktif untuk memunculkan video animasi. Salah satu interaksi yang dapat dilakukan pada multimedia interaktif adalah dengan tekan tombol yang berbeda untuk memunculkan tampilan video animasi ataupun gambar yang berbeda. Salah satunya dari tombol bagian keliling kantin yang dapat dilihat di Gambar 13. berikut ini.

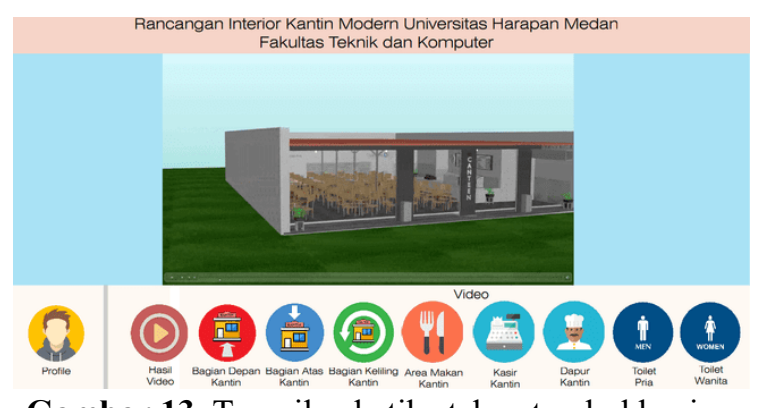

Gambar 13. Tampilan ketika tekan tombol bagian keliling kantin

Selanjutnya, penulis mengumpulkan responden terhadap video promosi yang sudah dibuat melalui link: bit.ly/kantinterbaru dimana yang melakukan pemilihan di kuesioner berjumlah 19 orang. Berikut pertanyaan yang ada di kuesioner

1. Pertanyaan 1: Bagaimana pendapatmu mengenai tampilan video animasi rancangan kantin Universitas Harapan Medan Fakultas Teknik dan Komputer?

2. Pertanyaan 2: Bagaimana durasi yang diberikan terhadap video animasi rancangan kantin Universitas Harapan Medan Fakultas Teknik dan Komputer?

3. Pertanyaan 3: Menurut kalian, apakah model rancangan kantin ini sesuai dengan kantin pada umumnya ?

4. Pertanyaa 4: Apakah video animasi rancangan kantin Universitas Harapan Medan Fakultas Teknik dan Komputer layak dijadikan sebagai promosi?

Dari pertanyaan ini, dikumpulkan pilihan yang diberikan oleh responden ke kuesioner. Berikut Hasil tiap penilaian responden yang dapat dilihat di bawah ini:

Tabel 2. Hasil Pilihan yang didapat dari kuesioner di pertanyaan pertama

\begin{tabular}{|c|c|c|c|c|}
\hline \multirow{2}{*}{ No. } & \multirow{2}{*}{$\begin{array}{c}\text { Urutan } \\
\text { Pertanyaan }\end{array}$} & \multicolumn{3}{|c|}{$\begin{array}{c}\text { Pilihan responden ke } \\
\text { kuesioner }\end{array}$} \\
\cline { 3 - 5 } & Bagus & Sedang & $\begin{array}{c}\text { Tidak } \\
\text { Bagus }\end{array}$ \\
\hline 1. & $\begin{array}{c}\text { Pertanyaan } \\
1\end{array}$ & $\begin{array}{c}16 \text { Orang } \\
(84,6 \%)\end{array}$ & $\begin{array}{c}3 \text { Orang } \\
(15,4 \%)\end{array}$ & $\begin{array}{c}0 \\
\text { Orang } \\
(0 \%)\end{array}$ \\
\hline
\end{tabular}


Tabel 3. Hasil Pilihan yang didapat dari kuesioner di pertanyaan kedua

\begin{tabular}{|c|c|c|c|c|}
\hline \multirow{2}{*}{ No. } & \multirow{2}{*}{$\begin{array}{c}\text { Urutan } \\
\text { Pertanyaan }\end{array}$} & \multicolumn{3}{|c|}{ Pilihan responden ke } \\
\cline { 3 - 5 } & & $\begin{array}{c}\text { Terlalu } \\
\text { Panjang }\end{array}$ & Sedang & $\begin{array}{c}\text { Terlalu } \\
\text { Pendek }\end{array}$ \\
\hline \multirow{2}{*}{1.} & Pertanyaan & $\begin{array}{c}1 \text { Orang } \\
(7,7 \%)\end{array}$ & $\begin{array}{c}18 \\
\text { Orang } \\
(92,3 \%)\end{array}$ & $\begin{array}{c}0 \\
\text { Orang } \\
(0 \%)\end{array}$ \\
\hline
\end{tabular}

Tabel 4. Hasil Pilihan yang didapat dari kuesioner di

\begin{tabular}{|c|c|c|c|}
\multicolumn{3}{|c|}{ pertanyaan ketiga } \\
\hline \multirow{2}{*}{ No. } & $\begin{array}{c}\text { Urutan } \\
\text { Pertanyaan }\end{array}$ & \multicolumn{2}{|c|}{$\begin{array}{c}\text { Pilihan responden ke } \\
\text { kuesioner }\end{array}$} \\
\cline { 3 - 4 } & & Sesuai & Tidak Sesuai \\
\hline \multirow{2}{*}{1.} & Pertanyaan & $\begin{array}{c}18 \text { Orang } \\
(92,9 \%)\end{array}$ & $\begin{array}{c}1 \text { Orang } \\
(7,1 \%)\end{array}$ \\
\hline
\end{tabular}

Tabel 5. Hasil Pilihan yang didapat dari kuesioner di pertanyaan keempat

\begin{tabular}{|c|c|c|c|}
\hline N & Urutan & \multicolumn{2}{|c|}{ Pilihan responden ke kuesioner } \\
\cline { 3 - 4 } o. & Pertanyaan & Layak & Tidak Layak \\
\hline \multirow{2}{*}{1.} & Pertanyaan & 17 Orang & 2 Orang \\
& 4 & $(85,7 \%)$ & $(14,3 \%)$ \\
\hline
\end{tabular}

\section{KESIMPULAN}

Berdasarkan hasil dan pembahasan yang telah dilakukan, video dapat tersampaikan kepada masyarakat dan direspon melalui google form. Respon sesuai dengan keinginan penulis dengan pilihan terbanyak dari tiap pertanyaan berdasarkan kuantitatif, diantaranya: Pertanyaan Pertama $=$ Bagus $(84,6 \%)$ dengan 16 orang, Pertanyaan Kedua = Sedang $(92,3 \%)$ dengan 18 orang, Pertanyaan Ketiga = Sesuai (92,9\%) dengan 18 orang dan Pertanyaan Keempat = Layak (85,7\%) dengan 17 orang.

Dengan hasil terbanyak yang didapatkan, maka video ini mendapat respon bagus dan dapat dijadikan sebagai video promosi kampus Universitas Harapan Medan Fakultas Teknik dan Komputer.

\section{DAFTAR PUSTAKA}

Adillasari, S. (2018). Pembuatan Model 3D Anatomi Telinga Manusia Untuk Aplikasi Viewer Pada PT. Penerbit Erlangga. KOPERTIP: Jurnal Ilmiah Manajemen Informatika Dan Komputer, 2(03), 137-142.

Awulle, M. E., Sentinuwo, S. R., \& Lumenta, A. S. M. (2016). Pembuatan Film Animasi 3D

Menggunakan Metode Dynamic Simulation.

Jurnal Teknik Elektro Dan Komputer, 5(4), 7079.

Cahyono, A. B., \& Rafitricia, A. N. (2017).
VISUALISASI MODEL 3D UNTUK SISTEM INFORMASI PENGGUNAAN GEDUNG (Studi Kasus : Gedung Teknik Geomatika, UPMB dan UPMS Kampus ITS). Journal of Geodesy and Geomatics, 12(2), 129-135. https://doi.org/10.12962/j24423998.v12i2.3583

Islami, L. U., \& Sembada, G. G. (2017). PERANCANGAN PROMOSI VISUAL RESTORAN “WARUNG SEKAR TAJI" VISUAL PROMOTION DESIGN. EProceeding of Art \& Design, 4(3), 359-374.

Komputer, W. (2002). Pembuatan Animasi dengan Macromedia Flash 5.0 (Pertama). Jakarta: Salemba Infotek.

Pramudia, R., Apriyani, M. E., \& Prasetyaningsih, S. (2016). ANALISIS DAN IMPLEMENTASI MEL SCRIPT UNTUK LIGHTING DAN RENDERING PADA FILM ANIMASI 3D ROBOCUBE. Ilmiah Komputer Dan Informatika (KOMPUTA), 5(1), 28.

Rapi, M., Aulia, R., \& Usman, A. (2019). Rancangan Gedung Serbaguna Universitas Harapan Fakultas Teknik Dan Komputer Sebagai Media Promosi Kampus Berbasis Animasi 3D. Snastikom 2019, 297-303.

Sonjaya, I., \& Zahra, A. (2017). Low Poly Modelling Interior Restoran pada Film Animasi 3D "Perjalanan Rempah-Rempah." Multinetics, 3(2), 38. https://doi.org/10.32722/vol3.no2.2017.pp38-44 